\title{
Polyacetylenes from Immature Seeds of Safflower (Carthamus tinctorius L.)
}

\author{
Ken-ichi IchiHara and Manjiro NodA \\ Department of Agricultural Chemistry, Faculty of Agriculture, \\ Kyoto Prefectural University, Kyoto, Japan \\ Received December 23, 1974
}

\begin{abstract}
Six polyacetylenes have been isolated from immature seeds of safflower (Carthamus finctorius L.) by thin-layer chromatography. They were identified as 1,11-tridecadiene3,5,7,9-tetrayne, 1,3,11-tridecatriene-5,7,9-triyne, 1,3,5,11-tridecatetraene-7,9-diyne, 1-tridecene3,5,7,9,11-pentayne, 1,3-tridecadiene-5,7,9,11-tetrayne and 1,3,5-tridecatriene-7,9,11-triyne from the results of their spectroscopic and chemical analyses. Three of these polyacetylenes had not been isolated from Carthamus tinctorius $\mathrm{L}$.

Changes in the polyacetylene content during maturation were followed by the measurement of ultraviolet absorbance. While 1,3,11-tridecatriene-5,7,9-triyne and 1,3,5,11-tridecatetraene7,9-diyne had already occurred abundantly at the day of flowering, the amounts of the other polyacetylenes reached the maximum values at the fourth to sixth days after flowering. A!though the total amounts of the six polyacetylenes were about $0.8 \mathrm{mmole} / \mathrm{g}$ lipid at the fourth day after flowering, no polyacetylene was detected in the mature seeds.
\end{abstract}

Bohlmann et $a l^{1,2)}$ have isolated many polyacetylenes from safflower roots and leaves, but the occurrence in its seeds has not been reported. Recently, two antifungal polyacetylenic diols have been isolated from Phytophthorainfected safflower stems, ${ }^{3 \sim 5}$ ) but not from its seeds.

In the course of an investigation of safflower lipids, nonpolar compounds containing conjugated systems of double and triple bonds have been detected in the lipids from the immature seeds by ultraviolet and infrared spectrometries.

The present paper deals with the isolation, purification and structure determination of these nonpolar polyacetylenic compounds in immature seeds of safflower. In addition, changes in amounts of the polyacetylenes during maturation were followed and the results were also described.

\section{MATERIAL AND METHODS}

Isolation and purification of polyacetylenes. Immature seeds of safflower (Carthamus tinctorius L.) were harvested at the third to eighth days after flowering and homogenized in chloroform-methanol $(1: 1$, v/v) with a Waring blender. The homogenate was filtered and the residue was re-extracted with chloroformmethanol $(1: 1, \mathrm{v} / \mathrm{v})$. To the combined extracts, water was added to separate chloroform layer, which was washed with water and dried over anhydrous sodium sulfate. After filtration and removal of the chloroform by evaporation in vacuo, the residual oil was dissolved in a small volume of diethyl ether and applied on preparative plates of Silica gel G (E. Merck, Darmstadt, Germany). When $n$-hexane-acetone $(95: 5, \mathrm{v} / \mathrm{v})$ was used as the developing solvent, polyacetylenes were separated from most other lipids and gave two yellow bands which were named as mixtures I ( $R f 0.58)$ and II $(R f 0.51)$. The individual bands were scraped separately and extracted several times with diethyl ether. For further separation of polyacetylene components in the two mixtures, thin-layer chromatography was carried out on silver nitrate-Silica gel $G$ plates ${ }^{6,7\rangle}$ which were prepared by coating with a slurry of $30 \mathrm{~g}$ of Silica gel $\mathrm{G}$ in $60 \mathrm{ml}$ of $12.5 \%$ aqueous siver nitrate (thickness: $0.5 \mathrm{~mm}$ ) and drying at $120^{\circ} \mathrm{C}$ for $3 \mathrm{hr}, n$-hexane-benzene $(95: 5, \mathrm{v} / \mathrm{v})$ being used as the developing solvent. Mixtures I and II separated into three yellow bands of polyacetylenes, respectively; those from mixture I were named as polyacetylenes Ia $(R f 0.61), \mathrm{Ib}(R f 0.42)$ and Ic $(R f 0.25)$, and those from mixture II as polyacetylenes IIa $(R f 0.61)$, IIb $(R f 0.42)$ and IIc ( $R f 0.25)$ (see Fig. 1).

The six polyacetylenes were further purified by thinlayer chromatography on Silica gel $G$ plates with carbon tetrachloride as the developing solvent. 


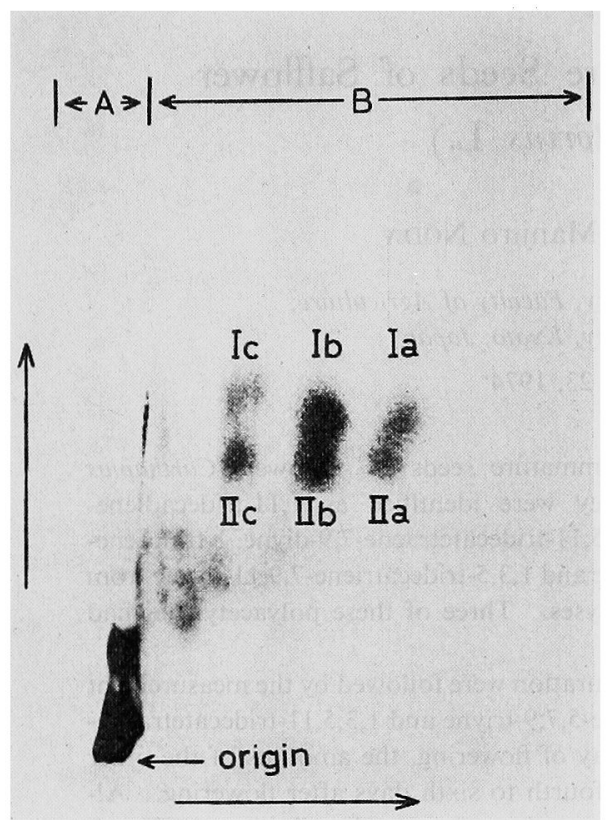

FIg. 1. Two-dimensional Thin-layer Chromatogram of Lipids Extracted from Immature Seeds of Safflower (Carthamus tinctorius $\mathbf{L}$.).

Development was first in the vertical direction with $n$-hexane-acetone $(95: 5, \mathrm{v} / \mathrm{v}$ ) on Silica gel G (area A), then in the horizontal direction with $n$-hexane-benzene (95: $5, \mathrm{v} / \mathrm{v})$ on Silica gel $\mathrm{G}$ impregnated by spraying with silver nitrate solution (area B). Spots were detected by charring at $120^{\circ} \mathrm{C}$ after spraying with $50 \%$ sulfuric acid.

Spectroscopic analyses. Ultraviolet spectra in diethyl ether or $n$-hexane were measured with a Hitachi 124 spectrophotometer. Infrared spectra in carbon tetrachloride were determined with a Shimadzu infrared spectrophotometer IR 27C. NMR spectra were obtained on a Hitachi R-24 NMR spectrometer (60 $\mathrm{MHz}$ ), with carbon tetrachloride as solvent, and tetramethylsilane was used as an internal standard.

Gas-liquid chromatography. Gas-liquid chromatographic analyses were performed at $120^{\circ} \mathrm{C}$ on a Shimadzu Gas Chromatograph GC-3AF with $3 \mathrm{~m} \times$ $3 \mathrm{~mm}$ (internal diameter) stainless steel column packed with $15 \%$ diethylene glycol succinate polyester on $60 \sim 80$ mesh Shimalite.

Catalytic hydrogenation. The polyacetylenes were hydrogenated in $n$-hexane over platinum black for $1.5 \mathrm{hr}$ at room temperature. The hydrogenation products were subjected to gas-liquid chromatography and elemental analysis.

The amount of hydrogen absorbed on a polyacetylene was estimated volumetrically, $n$-hexane-liquid paraffin $(1: 1, v / v)$ being used as solvent.
Determination of polyacetylene content in immature seeds of safflower. Immature seeds of safflower were harvested every other day after flowering and weighed. Lipids were extracted from the immature seeds with chloroform-methanol $(1: 1, \mathrm{v} / \mathrm{v})$ by the method similar to that described above, and the extract was dissolved in diethyl ether. The lipid content as estimated gravimetrically with an aliquot of the diethyl ether solution. Another aliquot of the solution was applied on Silica gel $\mathrm{G}$ plates impregnated with silver nitrate and developed with $n$-hexane-benzene $(95: 5, \mathrm{v} / \mathrm{v})$. As were expected, three polyacetylene fractions (polyacetylenes Ia plus IIa, Ib plus IIb, and Ic plus IIc) were obtained. Each polyacetylene was determined from the ultraviolet spectra of the three fractions.

\section{RESULTS AND DISCUSSION}

\section{Polyacetylene Ia}

The ultraviolet spectrum, with $\lambda_{\max } \mathrm{nm}(\varepsilon)$ at $258(95,900), 271(138,000), 287.5(108,000)$, $315(8,800), 336.5(14,600), 362(17,700)$ and $390.5(10,900)$, indicated that polyacetylene Ia contained an ene-tetrayne-ene chromophore. ${ }^{8)}$ The infrared spectrum showed the presence of triple bonds $\left(2125,2185 \mathrm{~cm}^{-1}\right)$, a vinyl group (929, 1284, $1860 \mathrm{~cm}^{-1}$ ) and a trans double bond $\left(948^{-1}\right)$, but exhibited neither allenic nor terminal acetylenic absorption. Two bands at 1377 and $1441 \mathrm{~cm}^{-1}$ seemed probably due to $\mathrm{C}-\mathrm{H}$ symmetric and asymmetric bending vibrations, respectively, in a methyl group. The amount of hydrogen required by the catalytic hydrogenation of polyacetylene Ia was 9.9 moles/mole $\left(\mathrm{C}_{13} \mathrm{H}_{8}\right.$ requires 10 moles/ mole). The hydrogenation product was identified as $n$-tridecane by comparing its gasliquid chromatogram with those of authentic straight-chain alkanes (Found: $\mathrm{C}, 84.72 ; \mathrm{H}$, 14.95. Calcd. for $\mathrm{C}_{13} \mathrm{H}_{28}$ : C, 84.69; H, $15.31 \%$ ). The linear nature of this hydrogenation product eliminated the possibility of branching or ring structure and established the carbon chain length in the original molecule.

On the basis of these data, polyacetylene Ia was identified as 1, 11-tridecadiene-3, 5, 7, 9tetrayne. $^{9 \sim 11)}$ This structure was well confirmed by the NMR data (Table I) and the results of the elemental analysis (Found: C, 94.90; H, 4.98. Calcd. for $\mathrm{C}_{13} \mathrm{H}_{8}: \mathrm{C}, 95.09 ; \mathrm{H}$, 
$4.91 \%$

\section{Polyacetylene $I b$}

A diethyl ether solution of polyacetylene $\mathrm{Ib}$ exhibited the following ultraviolet absorption properties: $\lambda_{\max } \mathrm{nm}(\varepsilon) 241.5 \quad(34,100), 272$ $(76,500), 287(71,400), 298.5(17,300), 309$ $(12,800), 318.5(27,100), 328.5(14,000), 341$ $(37,200), 351.5(10,000)$ and $366.5(28,100)$. These properties indicated the presence of an ene-triyne-diene chromophore ${ }^{8,12)}$ in the structure. The infrared spectrum exhibited a strong absorption band at $2170 \mathrm{~cm}^{-1}$, interpreted as a disubstituted $\mathrm{C} \equiv \mathrm{C}$ stretching frequency. Three high intensive absorption bands at 917,1283 and $1830 \mathrm{~cm}^{-1}$ indicated the presence of a vinyl group. The presence of a conjugated system of double bonds was inferred from a strong absorption band in the hydrogen bending region near $1000 \mathrm{~cm}^{-1}$ The hydrogenation of polyacetylene $\mathrm{Ib}$ was completed with a consumption of 9.2 moles/ mole of hydrogen $\left(\mathrm{C}_{13} \mathrm{H}_{10}\right.$ requires 9 moles/ mole). The hydrogenation product was identified as $n$-tridecane by gas-liquid chromatography (Found: C, 84.67; H, 14.92. Calcd. for $\mathrm{C}_{13} \mathrm{H}_{28}: \mathrm{C}, 84.69 ; \mathrm{H}, 15.31 \%$ ).

All of these data and the NMR spectrum (see Table I) showed that the structure of polyacetylene Ib was 1, 3, 11-tridecatriene-5, 7, 9 triyne $^{10,13,14)}$ (Found: C, 93.81; H, 6.27. Calcd. for $\mathrm{C}_{13} \mathrm{H}_{10}: \mathrm{C}, 93.94 ; \mathrm{H}, 6.06 \%$ ).

\section{Polyacetylene Ic}

Polyacetylene Ic had $\lambda_{\max } \mathrm{nm}(\varepsilon)$ at 264.5 $(30,500), \quad 274(26,3000), \quad 313(37,100), \quad 329$ $(50,800)$ and $353(39,400)$. This ultraviolet absorption pattern supported the idea that the chromophore of polyacetylene Ic was enediyne-triene. $^{8)}$ The infrared spectrum showed two bands at 2120 and $2185 \mathrm{~cm}^{-1} \quad(\mathrm{C} \equiv \mathrm{C}$ stretching). No indication of the presence of allenic group was found and, moreover, an acetylenic $\mathrm{C}-\mathrm{H}$ stretching band near $3300 \mathrm{~cm}^{-1}$

Table I. NMR Spectral Data of the Six Polyacetylenes Isolated from ImMature SeEds of SAFflower (Carthamus tinctorius L.)

$\begin{array}{ccccc}a & b & c & d & e \\ \text { (Ia) } \mathrm{CH}_{3} \mathrm{CH} & =\mathrm{CH} & (\mathrm{C}=\mathrm{C})_{4} \mathrm{CH}=\mathrm{CH}_{2}\end{array}$

\begin{tabular}{lllr}
\hline & $\mathrm{H}$ & \multicolumn{1}{c}{$\delta(\mathrm{ppm})$} & $J(\mathrm{~Hz})$ \\
\hline$a$ & & $1.86(\mathrm{dd})$ & $5.7,1.3$ \\
$b$ & & $6.41(\mathrm{dq})$ & $15.8,5.7$ \\
$c$ & $5.49(\mathrm{dq})$ & $15.8,1.3$ \\
$d, e$ & $5.3 \sim 6.1(\mathrm{~m})$ & - \\
\hline
\end{tabular}

$\begin{array}{llllllll}a & b & c & d & e & f & g & h\end{array}$

(Ic) $\mathrm{CH}_{3} \mathrm{CH}=\mathrm{CH}(\mathrm{C} \equiv \mathrm{C})_{2} \mathrm{CH}=\mathrm{CHCH}=\mathrm{CHCH}=\mathrm{CH}_{2}$

\begin{tabular}{llc}
\hline \multicolumn{1}{c}{$\mathrm{H}$} & \multicolumn{1}{c}{$(\mathrm{ppm})$} & $J(\mathrm{~Hz})$ \\
\hline$a$ & $1.84(\mathrm{dd})$ & $5.7,1.2$ \\
$b, c, d, e, f, g, h, i$ & $5.0 \sim 7.4(\mathrm{~m})$ & - \\
\hline
\end{tabular}

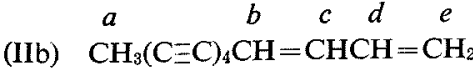

\begin{tabular}{llll} 
& $\mathrm{H}$ & \multicolumn{1}{c}{$\delta(\mathrm{ppm})$} & $J(\mathrm{~Hz})$ \\
\hline$a$ & & $2.02(\mathrm{~s})$ & - \\
$b, e$ & $5.1 \sim 5.8(\mathrm{~m})$ & - \\
$c, d$ & $6.0 \sim 7.2(\mathrm{~m})$ & - \\
\hline
\end{tabular}

$\begin{array}{lllllll}a & b & c & d & e & f & g\end{array}$

(Ib) $\mathrm{CH}_{3} \mathrm{CH}=\mathrm{CH}(\mathrm{C} \equiv \mathrm{C})_{3} \mathrm{CH}=\mathrm{CHCH}=\mathrm{CH}_{2}$

\begin{tabular}{cccc}
\hline & $\mathrm{H}$ & \multicolumn{1}{c}{$\delta(\mathrm{ppm})$} & $J(\mathrm{~Hz})$ \\
\hline$a$ & $1.84(\mathrm{dd})$ & $5.7,1.3$ \\
$b, e, f$ & $6.0 \sim 7.2(\mathrm{~m})$ & - \\
$c, d, g$ & $5.0 \sim 5.8(\mathrm{~m})$ & - \\
\hline
\end{tabular}

$\begin{array}{ccc}a & b\end{array}$

(IIa) $\mathrm{CH}_{3}\left(\mathrm{C}_{-}^{-} \mathrm{C}\right)_{5} \mathrm{CH}=\mathrm{CH}_{2}$

\begin{tabular}{|c|c|c|}
\hline $\mathrm{H}$ & $\delta(\mathrm{ppm})$ & $J(\mathrm{~Hz})$ \\
\hline$a$ & $2.02(\mathrm{~s})$ & - \\
\hline$b, c$ & $5.5 \sim 6.1(\mathrm{~m})$ & - \\
\hline
\end{tabular}

$\begin{array}{lllllll}a & b & c & d & e & f\end{array}$

(IIc) $\mathrm{CH}_{3}(\mathrm{C}=\mathrm{C})_{3} \mathrm{CH}=\mathrm{CHCH}=\mathrm{CHCH}=\mathrm{CH}_{2}$

\begin{tabular}{lll}
\multicolumn{1}{c}{$\mathrm{H}$} & \multicolumn{1}{c}{$\delta(\mathrm{ppm})$} & $J(\mathrm{~Hz})$ \\
\hline$a$ & $2.01(\mathrm{~s})$ & - \\
$b, c, d, e, f, g$ & $5.0 \sim 7.3(\mathrm{~m})$ & - \\
\hline
\end{tabular}

s: singlet; dd: double doublet; dq: double quartet; m: multiplet. 
was absent. A strong absorption band at $1005 \mathrm{~cm}^{-1}$ indicated the presence of a conjugated system of double bonds. One of the terminal groups was a vinyl group (906, 1282, $1813 \mathrm{~cm}^{-1}$ ). The NMR spectrum (see Table I) indicated that the other end was a 1-propenyl group. The complete catalytic hydrogenation required 7.8 moles/mole of hydrogen $\left(\mathrm{C}_{13} \mathrm{H}_{12}\right.$ requires $8 \mathrm{moles} / \mathrm{mole}$ ) and gave $n$-tridecane (Found: C, 84.45; H, 15.37. Calcd. for $\mathrm{C}_{13} \mathrm{H}_{28}$ : C, $84.69 ; \mathrm{H}, 15.31 \%$ ).

These data led to the formulation of polyacetylene Ic as 1, 3, 5, 11-tridecatetraene-7, 9diyne $^{11,15)}$ (Found: C, 93.19; H, 7.13. Calcd. for $\mathrm{C}_{13} \mathrm{H}_{12}: \mathrm{C}, 92.81 ; \mathrm{H}, 7.19 \%$ ).

\section{Polyacetylene IIa}

This polyacetylene possessed the following ultraviolet absorption maxima due to an ene-

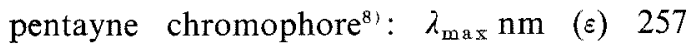
$(122,000), 265(173,000), 270(147,000), 286$ $(137,000), 328.5(3200), 351.5(5200), 378.5$ (5700) and $410(3100)$. The infrared spectrum exhibited four prominent absorption bands at $2100,2170,2200$ and $2230 \mathrm{~cm}^{-1} \quad(\mathrm{C} \equiv \mathrm{C}$ stretching). The presence of a terminal vinyl group was indicated by the characteristic absorption bands at 928,1284 and $1860 \mathrm{~cm}^{-1}$ The NMR data (Table I) showed that the other end of the molecule was a methyl group and the adjacent carbon atom had no hydrogen atom. The hydrogenation of polyacetylene IIa required 10.9 moles/mole of hydrogen $\left(\mathrm{C}_{13} \mathrm{H}_{6}\right.$ requires 11 moles $/$ mole). The gas-liquid chromatographic retention time of the hydrogenation product agreed with that of authentic $n$-tridecane (Found: C, 84.99; H, 15.32. Calcd. for $\mathrm{C}_{13} \mathrm{H}_{28}$ : C, 84.69; $\mathrm{H}, 15.31 \%$ ). Therefore, polyacetylene IIa could be formulated as 1-tridecene-3, 5, 7, 9, 11-pentayne. ${ }^{9,16)} \mathrm{Be}$ cause of the extreme instability, especially in the crystalline state, the elemental analysis of this polyacetylene could not be carried out.

\section{Polyacetylene $\mathrm{IIb}$}

The ultraviolet spectrum, with $\lambda_{\max } \mathrm{nm}(\varepsilon)$ at $263.5(42,200), 274.5(86,200), 290.5(164,000)$ $311(16,400), 331.5(27,100), 355.5(33,200)$ and
$383(21,600)$, indicated that polyacetylene IIb contained a diene-tetrayne chromophore. ${ }^{8}$ The absorption bands at the infrared region were assigned as follows: 2140, 2160 and $2215 \mathrm{~cm}^{-1}(\mathrm{C} \equiv \mathrm{C}) ; 919,1284$ and $1837 \mathrm{~cm}^{-1}$ $\left(\mathrm{CH}=\mathrm{CH}_{2}\right) ; 941 \mathrm{~cm}^{-1} \quad($ trans $\mathrm{CH}=\mathrm{CH})$; $999 \mathrm{~cm}^{-1}(\mathrm{CH}=\mathrm{CHCH}=\mathrm{CH}) ; 1373$ and $1432 \mathrm{~cm}^{-1}\left(\mathrm{CH}_{3}\right)$. No absorption band characteristic of terminal ethynyl groups was observed. A single peak at $\delta 2.02 \mathrm{ppm}$ in the NMR spectrum (see Table I) revealed that no hydrogen atom bound to the carbon atom adjacent to the terminal methyl group. The hydrogenation of polyacetylene IIb was complete with an uptake of 10.2 moles/mole of hydrogen $\left(\mathrm{C}_{13} \mathrm{H}_{8}\right.$ requires 10 moles/mole. and the product was confirmed to be $n$-tridecane by gas-liquid chromatography (Found: C, 84.82; $\mathrm{H}$, 14.91. Calcd. for $\mathrm{C}_{13} \mathrm{H}_{28}: \mathrm{C}$, $84.69 ; \mathrm{H}, 15.31 \%$ ).

On the basis of these data, polyacetylene $\mathrm{IIb}$ was identified as 1, 3-tridecadiene-5, 7, 9, 11tetrayne. ${ }^{17}$ The results of the elemental analysis were in good agreement with the calculated values (Found: C, 95.12; H, 5.15. Calcd. for $\mathrm{C}_{13} \mathrm{H}_{8}: \mathrm{C}, 95.09, \mathrm{H}, 4.91 \%$ ).

\section{Polyacetylene IIc}

The ultraviolet spectrum was very similar to that recorded for a polaycetylenic hydrocarbon, 1, 3, 5-tridecatriene-7, 9, 11-triyne isolated from Achillea ptarmica L. by Bohlmann et al., ${ }^{18,19)}$ though the $\varepsilon$ values of polyacetylene IIc were lower than those of the known polyacetylenic hydrocarbon. $\lambda_{\max } \mathrm{nm} \quad(\varepsilon): 266.5 \quad(27,500)$, $271.5(40,500), 284(74,200), 313(30,400)$, $332.5(50,300)$ and $355(44,900)$. In spite of the discrepancies in intensity, the characteristic fine structure (especially at $250 \sim 280 \mathrm{~nm}$ ) left no doubt that the two substances were identical. The infrared absorption bands due to a vinyl group were observed at 906, 1281 and 1815 $\mathrm{cm}^{-1}$, and a sharp band at $1004 \mathrm{~cm}^{-1}$ seemed probably due to a $\mathrm{C}-\mathrm{H}$ out-of-plane bending mode in a conjugated system of double bonds. A band at $1379 \mathrm{~cm}^{-1}$ in the infrared spectrum and a single peak at $\delta 2.01 \mathrm{ppm}$ in the NMR spectrum (see Table I) indicated that the one 
end of the molecule terminated with a methyl group adjacent to an acetylenic carbon. The hydrogenation of polyacetylene IIc required 8.9 moles/mole of hydrogen $\left(\mathrm{C}_{13} \mathrm{H}_{10}\right.$ requires 9 moles/mole), and the hydrogenation product was identified as $n$-tridecane by gas-liquid chromatography (Found: C, 85.38; H, 15.05 . Calcd. for $\mathrm{C}_{13} \mathrm{H}_{28}: \mathrm{C}, 84.69 ; \mathrm{H}, 15.31 \%$ ).

These data togather with the results of the elemental analysis also supported the idea that polyacetylene IIc was 1, 3, 5-tridecatriene7, 9, 11-triyne (Found: C, 93.90; H, 6.48. Calcd. for $\mathrm{C}_{13} \mathrm{H}_{10}: \mathrm{C}, 93.94 ; \mathrm{H}, 6.06 \%$ ).

Polyacetylenes Ic, IIa and IIb have not hitherto been isolated from Carthamus tinctorius $\mathrm{L}$., while polyacetylenes $\mathrm{Ia}, \mathrm{Ib}$ and IIc have been isolated from its roots and leaves. ${ }^{1,20)}$

\section{Changes in polyacetylene content during maturation}

Figure 2 shows that the individual polyacetylenes are drastically metabolized during matura-

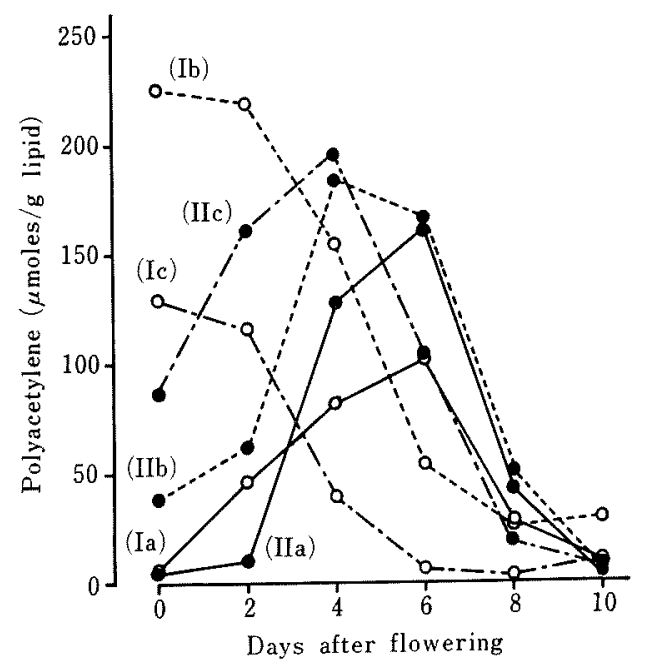

FIG. 2. Changes in Polyacetylene Content during Maturation.

$\mathrm{O}-\mathrm{O}$, polyacetylene $\mathrm{Ia} ; \mathrm{O}--\mathrm{O}$, polyacetylene Ib; $\bigcirc--\mathrm{O}$, polyacetylene Ic; $-\infty$, polyacetylene IIa; --o, polyacetylene IIb; --・, polyacetylene IIc.

tion. With increasing unsaturation of a polyacetylene, it tends to appear later in the immature seeds. In the case of polyacetylene IIa containing five conjugated triple bonds, even a lag period was observed. Disappearance of these polyacetylenes with proceeding maturation indicates that they will be converted into other non-polyacetylenic compounds during this period.

The total lipid contents per fresh weight of immature seeds remained approximately constant (about $1 \%$ ) until the tenth day after flowering except at the day of pollination, though they increased to about $10 \%$ at the twentieth day. The relationship between the decreasing of the polyacetylenes and the increasing of lipids during maturation may suggest that the polyacetylenes derive from lipids ${ }^{21 \prime}$ or closely relate to lipid metabolism.

\section{REFERENCES}

1) F. Bohlmann, S. Köhn and C. Arndt, Chem. Ber., 99, 3433 (1966).

2) F. Bohlmann and C. Zdero, ibid., 103, 2853 (1970).

3) C. A. Thomas and E. H. Allen, Phytopathology, 60, 261 (1970).

4) E. H. Allen and C. A. Thomas, Phytochemistry, 10, 1579 (1971).

5) E. H. Allen and C. A. Thomas, Phytopathology, 61, 1107 (1971).

6) C. B. Barrett, M. S. J. Dallas and F. B. Padley, Chem. Ind., 1962, 1050.

7) C. B. Barrett, M. S. J. Dallas and F. B. Padley, J. Amer. Oil Chem. Soc., 40, 580 (1963).

8) F. Bohlmann, T. Burkhardt and C. Zdero, "Naturally Occurring Acetylenes," Academic Press Inc., London, 1973, pp. 3 27.

9) E. R. H. Jones, L. Skatteb $\rho 1$ and M. C. Whiting, J. Chem. Soc., 1958, 1054.

10) F. Bohlmann and P. Herbst, Chem. Ber., 91, 1631 (1958).

11) J. S. Sörensen and N. A. Sörensen, Acta Chem. Scand., 8, 1741 (1954).

12) J. S. Sörensen and N. A. Sörensen, ibid., 8, 1763 (1954).

13) F. Bohlmann, S. Postulka and J. Ruhnke, Chem. Ber., 91, 1642 (1958).

14) J. S. Sörensen and N. A. Sörensen, Acta Chem. Scant., 12, 756 (1958).

15) F. Bohlmann and H. J. Mannhardt, Chem. Ber., 88, 1330 (1955).

16) J.S. Sörensen, D. Holme, E. T. Borlaug and N. A. Sörensen, Acta Chem. Scand., 8, 1769 (1954).

17) F. Bohlmann, U. Hinz, A. Seyberlich and J. Repplinger, Chem. Ber., 97, 809 (1964).

18) F. Bohlmann, C. Arndt, H. Bornowski, H. Jastrow and K. M. Kleine, ibid., 95, 1320 (1962). 
19) F. Bohlmann and H. Jastrow, Chem. Ber., 95, 1742 (1962).

20) F. Bohlmann, T. Burkhardt and C. Zdero, "Naturally Occurring Acetylenes," Academic
Press Inc., London, 1973, p. 460.

21) F. Bohlmann, T. Burkhardt and C. Zdero, "Naturally Occurring Acetylenes," Academic Press Inc., London, 1973, pp. 257 258. 